\title{
Recent developments in modeling the hot working behavior of metallic materials
}

\author{
V V KUTUMBARAO* and T RAJAGOPALACHARY ${ }^{\dagger}$ \\ Department of Metallurgical Engineering, Banaras Hindu University, Varanasi 221005 , India \\ ${ }^{\dagger}$ Department of Metallurgical Engineering, Jawaharlal Nehru Technological University, \\ Hyderabad 500872 , India
}

MS received 30 August 1995

\begin{abstract}
Three distinct trends in the modeling of hot working behavior of metallic materials are identified. These are respectively (a) analytical and numerical methods to characterize the material flow behavior and related macroscopic properties, (b) metallurgical models to predict microstructural parameters at each step in a multi-step processing operation, and (c) hot workability models to predict optimum conditions of temperature and strain rate for a single step deformation. Important features of the models are critically examined and some possible directions for future work indicated.
\end{abstract}

Keywords. Hot working; modeling; microstructural control; processing maps.

\section{Introduction}

Mechanical working of metals at high homologous temperatures $\left(T>0.5 T_{\mathrm{m}}\right)$ is known as hot working. The final product may be obtained from the workpiece either in a single step involving large deformation or a series of steps each of which imparts only a small deformation. Obtaining a sound defect free product with close dimensional tolerances is the primary objective of the common metal working operations such as rolling, forging and extrusion. 'Right the First Time' manufacturing is becoming increasingly important in the hot working industry. Also net shape and near net shape technologies are becoming common. The physical and mathematical modeling of hot working processes is a cost effective and speedy route to process optimization and process development. This kind of modeling enables the forming engineer to obtain information such as the load and power required to accomplish the shape change, the maximum allowable strain in a given step in the sequence of forming operations, the stress and velocity distributions in the component, optimum process conditions like temperature and strain rate and probable location of defects. It facilitates a reduction in die and tool design costs as well as the product and process developmental expenditure.

A mathematical model may be defined as a set of differential equations which provides a quantitative description of the hot working process. The entire process or only some specific aspects of it may be modeled. Several conventional methods of varying complexity such as the slab method have been in use in hot working computations (figure 1). While these give a first order estimate of the quantities of interest to a forming engineer, they are inadequate in meeting all the information requirements.

Recent developments in mathematical modeling of hot working have been taking place along three major directions. The first is the activity related to numerical simulation of metal flow during hot working of components. While the finite difference, finite element and boundary element methods are in vogue, the finite element method has been by far the most popular. Metal flow simulation models consider the workpiece 
(A) SLAB METHOD

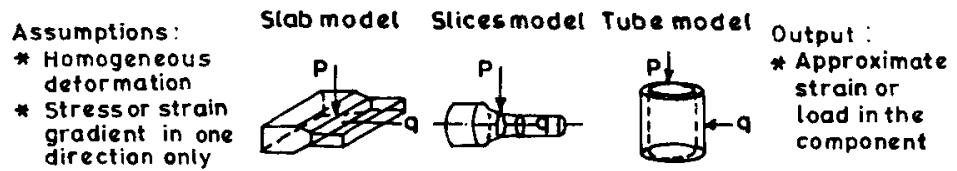

(B) SLIP LINE FIELD METHOD
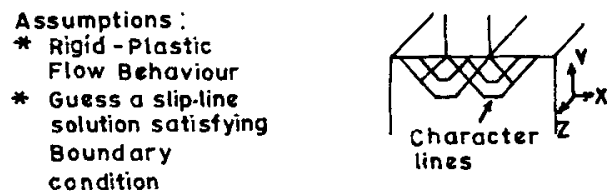

Limitations:

* Provides load

Estimate only

* Tedious, Solutions

Difficult to verify

* Non uniqueness

of solution

(C) UPPER BOUND METHOD

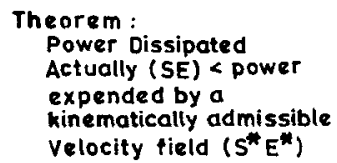

velocity field $\left(S^{*} E^{*}\right)$

(D) LOWER BOUND METHOD

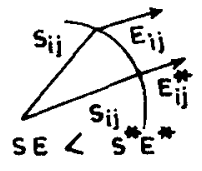

Output:

Provides estimate of minimum power and load in forming a component

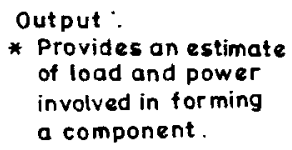

* Provides an estimate of load and power involved in forming a component.

Power actually dissipated > power expended by statically admissible stress field.

Figure 1. Conventional methods of modeling in metal forming.

to be a macroscopically homogeneous continuum possessing definite rheological properties. Microstructural changes occurring during and after deformation are not considered. This type of mathematical modeling is discussed in section 2 . The second recent development is in the design of manufacturing schedules which result in desired microstructures in a consistent fashion, such as in the controlled rolling of HSLA steels (Sekine et al 1982; Roberts et al 1984). The initial conceptualization of such methods and the thrust for continued efforts came from Sellars $(1980,1990)$. Based on empirical relations for microscopic phenomena such as dynamic recovery, dynamic recrystallization, static recovery, static recrystallization and grain growth, this methodology, also described in section 2, aims at calculation of microstructural parameters like grain size at each of several steps in the processing schedule. The third recent trend is to model the intrinsic hot workability of the material and to determine the optimum working conditions for processing in a single step. Models with this perspective are useful in materials development and characterization programmes. The dynamic materials model and the polar reciprocity model are two examples in this category. These are discussed in section 3 .

\section{Numerical and phenomenological models}

Conventionally, modeling of metal forming processes has been made by methods such as the slab method, slip-line field method and upper or lower bound methods (Altan 
Table 1. Summary of analytical and numerical models of metal forming (Altan et al 1983).

\begin{tabular}{|c|c|c|c|c|c|c|c|}
\hline \multirow[b]{3}{*}{ Method } & \multirow{2}{*}{\multicolumn{2}{|c|}{ Input }} & \multicolumn{4}{|c|}{ Output } & \multirow[b]{3}{*}{ Comments } \\
\hline & & & \multirow{2}{*}{$\begin{array}{l}\text { Velocity } \\
\text { field }\end{array}$} & \multirow{2}{*}{$\begin{array}{l}\text { Stress } \\
\text { field }\end{array}$} & \multirow{2}{*}{$\begin{array}{l}\text { Temp. } \\
\text { field }\end{array}$} & \multirow{2}{*}{$\begin{array}{l}\text { Stresses } \\
\text { on tools }\end{array}$} & \\
\hline & Flex stress & Friction & & & & & \\
\hline Slab & Average & (a)(b) & No & Yes & No & Yes & Ignores redundant work \\
\hline $\begin{array}{l}\text { Uniform } \\
\text { energy }\end{array}$ & Average & (b) & No & No & No & Average & $\begin{array}{l}\text { Redundant work can be } \\
\text { included approximately }\end{array}$ \\
\hline Slip line & Average & $(a)(b)$ & Yes & Yes & No & Yes & $\begin{array}{l}\text { Valid for plane-strain } \\
\text { problems }\end{array}$ \\
\hline $\begin{array}{l}\text { Upper } \\
\text { bound }\end{array}$ & Distribution & (b) & Yes & No & No & Average & $\begin{array}{l}\text { Gives upper bound on } \\
\text { loads, can determine } \\
\text { free boundaries }\end{array}$ \\
\hline Hill's & Distribution & $(a)(b)$ & Yes & No & No & Average & Can treat 3-D problems \\
\hline $\begin{array}{l}\text { Finite } \\
\text { difference }\end{array}$ & Distribution & $(a)(b)$ & Yes & Yes & Yes & Yes & $\begin{array}{l}\text { Requires considerable } \\
\text { computer time }\end{array}$ \\
\hline $\begin{array}{l}\text { Finite } \\
\text { element }\end{array}$ & Distribution & (a)(b) & Yes & Yes & Yes & Yes & Same as above \\
\hline $\begin{array}{l}\text { Matrix } \\
\text { Weighted }\end{array}$ & Distribution & (a)(b) & Yes & Yes & Yes & Yes & $\begin{array}{l}\text { Treats rigid/plastic } \\
\text { material }\end{array}$ \\
\hline $\begin{array}{l}\text { residuals } \\
\text { (a) } \tau=\mu \sigma_{n},(\end{array}$ & $\begin{array}{l}\text { Distribution } \\
\text { b) } \tau=m \bar{\sigma} / \sqrt{3}\end{array}$ & $(a)(b)$ & Yes & Yes & Yes & Yes & Very general approach \\
\hline
\end{tabular}

et al 1983). The slab method is based on the assumption that metal deformation is homogeneous and that stress or strain gradients in the material exist only in one direction. In this method, the workpiece is considered to be divisible into either slabs, slices or tubes. This method aims at a closed form solution to the metal flow equations. It provides an estimate of strain or load borne by the component. The slip-line field method gives some insight into the pattern of material flow. However the method applies rigorously to plane strain deformation of a rigid, perfectly plastic isotropic solid unless artificially modified (Blazynski 1983). It cannot take into account strain hardening as also redundant and frictional aspects of deformation (Collins 1968; Johnson et al 1982). The upper and lower bound theorems provide respectively the upper and lower bounds on power required in plastic flow and estimate of the load required (Thomsen et al 1965). They are based on the theory of limit analysis and assume reasonable stress and velocity fields. The limitations, applicability and usefulness of different methods in analysing metal forming problems have been discussed by Altan and Lahoti (1979). Each of these methods can give only a part of the total information that is most often necessary. For example while the slab method permits calculation of the stress distribution in the workpiece, it does not provide any information about the velocity field. The reverse is true in case of upper and lower bound methods. None of the methods can output the temperature field (table 1).

\subsection{Finite element analysis}

Finite element analysis of flow simulation enables the forming engineer to obtain direct information about time dependent fields such as velocity or displacement as also the stress tensor and the temperature (Owen and Hinton 1980). From the velocity or 
displacement fields the changing shape of the workpiece can be determined. From the stress field tensor the working load or torque can be determined. The finite element method (FEM) has practical utility in preform and process design, assurance of die fill, optimizing the forming steps, flashless process design of forgings, tool design, billet shape and size optimization, die parting line determination, evaluation of grain flow and defect prognosis. The method involves the discretization of the component geometry into suitable elements, derivation of the element equations from the field equations based on continuity and/or compatibility conditions and the constitutive relations, assembly of element equations, imposition of initial or boundary values of local and global constraints, numerical solution of the set of equations generated and post processing of the evaluated quantities. For the treatment of plastic flow problems the analysis is carried out in incremental steps and may also involve use of iteration in any given incremental step. This is because of the nonlinear nature of plastic deformation and the finite strains involved in metal forming.

The early eighties witnessed the formulation of a coupled analysis of viscoplastic deformation and heat transfer involved in the metal forming problem. For example, Rebelo and Kobayashi (1980a, b) conducted a coupled analysis of viscoplastic deformation and heat transfer involved in the upsetting of a solid cylinder between two plattens. Huetink (1982) employed a mixed Euler-Lagrangian method for simulating thermomechanical forming problems. Subsequent developments in combined thermomechanical analysis have been rapid and several two- and three-dimensional finite element programs have been developed to model the metal flow in different forming processes. These programs differ from one another in the complexity with which the problem is mathematically formulated, the rheological behavior modeled (Shimazaki and Thompson 1981), the way friction is accounted for, the nature of the analysis attempted (transient or steady state), the reference frame used to characterize the deformation and other tensors (Eulerian, Lagrangian, or an updated Lagrangian etc.), the way thermomechanical coupling is modeled (Rebelo and Kobayashi 1980; Argyris and Boltsinis 1981), and the way the mesh is renewed (Gelten and Konter 1982; Badawy et al 1983; Boer and Rydstad 1984). In the simulation of hot rolling by finite element analysis several research groups have been active (Kobayashi 1982; Beynon et al 1986; Grober et al 1986; Huetink et al 1988; Kopp et al 1988; Pietrzyk et al 1986; Amici et al 1989; Montimitonnet and Buessler 1991).

While several of these models deal exclusively with the metal flow and/or heat transfer involved in the process, some formulations considering the thermomechanicalmicrostructural coupling have also been proposed. For example Rantanen et al (1989) combined a general purpose finite element package called ABAQUS with MICROPLA, which is a model for microstructure evolution. This combination leads to a weak coupling in which the solution iterates through the heat transfer, metal flow simulation and microstructural aspects of the problem. However, experimental validation of mechanical and thermal aspects of metal flow has been done only for a few simple geometries and boundary conditions such as uniaxial compression or plate rolling. Studies on validation of the microstructural part in this weak or sequential thermomechanical coupling are few. This is particularly true for nonsteady metal flow problems (Pietrzyk et al 1994).

A critical review of the state of finite strain plasticity has been provided by Naghdi (1990). Several problem areas still exist in finite strain plasticity where there is no general consensus. These include identification of plastic strain, admissibility of 
additional variables representing work hardening, invariance properties of variables characterizing plastic strain and work hardening, the number and nature of yield criteria, primacy of stress space or strain space formulations of yielding, validity of the associated flow rule, superiority of Eulerian description over Lagrangian description, splitting of velocity tensor, choice of deformation rate tensor and introduction of orientation variables or tensors. These differences in fundamental issues are bound to result in significantly different predictions of the field quantities by the finite element formulations which depend on how these fundamental issues are accounted for in the problem description. While there are many theories of finite strain plasticity with differing mathematical and computational complexity, experimental validation of most of these models is lagging behind. Thus circumspection is necessary in choosing the appropriate constitutive equation for characterizing metal flow in hot working by the finite element method.

Because of the large number of variables in metal flow simulation, the number of degrees of freedom rapidly becomes quite large for any three-dimensional analysis. Automatic and adaptive remeshing becomes necessary because of distortion of the finite element mesh at large strains. Due to this computational complexity, the published literature has been by and large in the nature of demonstration of the capabilities and underlying principles of the method proposed rather than problem solving involving complex geometries of actual components. However flow simulations are expected to become more common as experience with various FEM codes increases, cost of hardware dwindles and high performance graphics engines and more powerful algorithms become available.

A good engineering judgement and prior intuition is necessary for making use of solutions offered by the finite element analysis for optimization of component, preform and tool geometries. Finite element analysis usually assumes that the material is a homogeneous continuum so that the apparatus of continuum physics can be used. Changes in the internal structure are usually considered to reflect on the rheological behavior. But the evolution of microstructure, as it occurs with increasing strain and number of forming steps, cannot be predicted by the general formulations of the finite element method. A novel method of calculating the microstructure, which may be characterized by a parameter like the prior austenite grain size in steels, has been formulated by Sellars and coworkers. This is described in the next section.

\subsection{Sellars methodology}

Many hot working schedules involve discrete strain steps interspersed with pause periods. The pause periods could range from a few hundredths of a second for rolling of wire rod to about one minute in flat rolling and forging operations. The deformation in a given step is usually small. Extrusion and plate rolling are the two exceptions where reductions greater than $80 \%$ in a single step are common. Microstructural changes such as dynamic recovery or dynamic recrystallization may occur during deformation. Similarly microscopic phenomena like static recovery, static recrystallization, metadynamic recrystallization and grain growth may also occur during inter-pass pauses. Thus the final structure obtained in the hot worked component is a net result of its thermal and deformation history. Sellars and coworkers (Sellars and Whiteman 1979) have considered the different microscopic phenomena given above and provided 


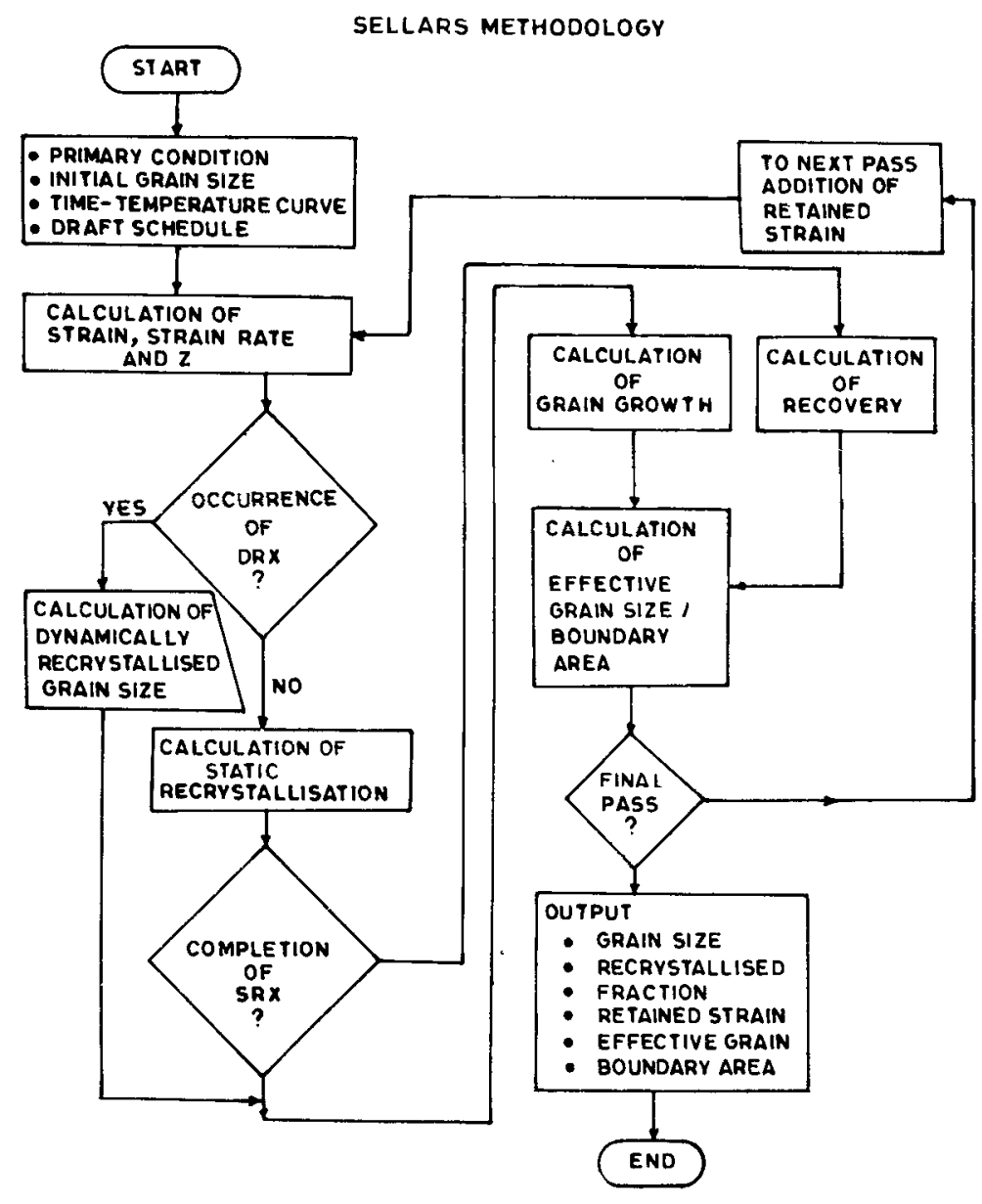

Figure 2. A block diagram of Sellars methodology.

algorithms for calculating the recrystallized fraction, grain size and grain boundary area. Starting with a reheated microstructure, changes in the grain size produced as a result of recrystallization, recovery and grain growth following the first working step are computed. The updated value is used as the initial grain size for the second pass and so on in an iterative manner. The kinetics of each of the phenomena as a function of time and strain are followed independently and their influence on the microstructure and mechanical properties is calculated at every step. The kinetics of the phenomena depend on the initial microstructure and the processing conditions. A block diagram of the algorithm used by Sellars (1980) is shown in figure 2 . The inputs here are the initial grain size, the time-temperature profile, and the rolling parameters such as the rolling speed, diameter of rolls and the degree of reduction attempted. The algorithm makes use of empirical and phenomenological kinetic equations. Extensive laboratory testing is used to evolve the phenomenological or empirical equations and associated material constants. The output consists of the specific grain boundary area, the retained strain and the grain size.

This approach has been nourished by contributions from a number of research groups (Ahlblom and Roberts 1979; Sellars and Whiteman 1979; Parthington and 


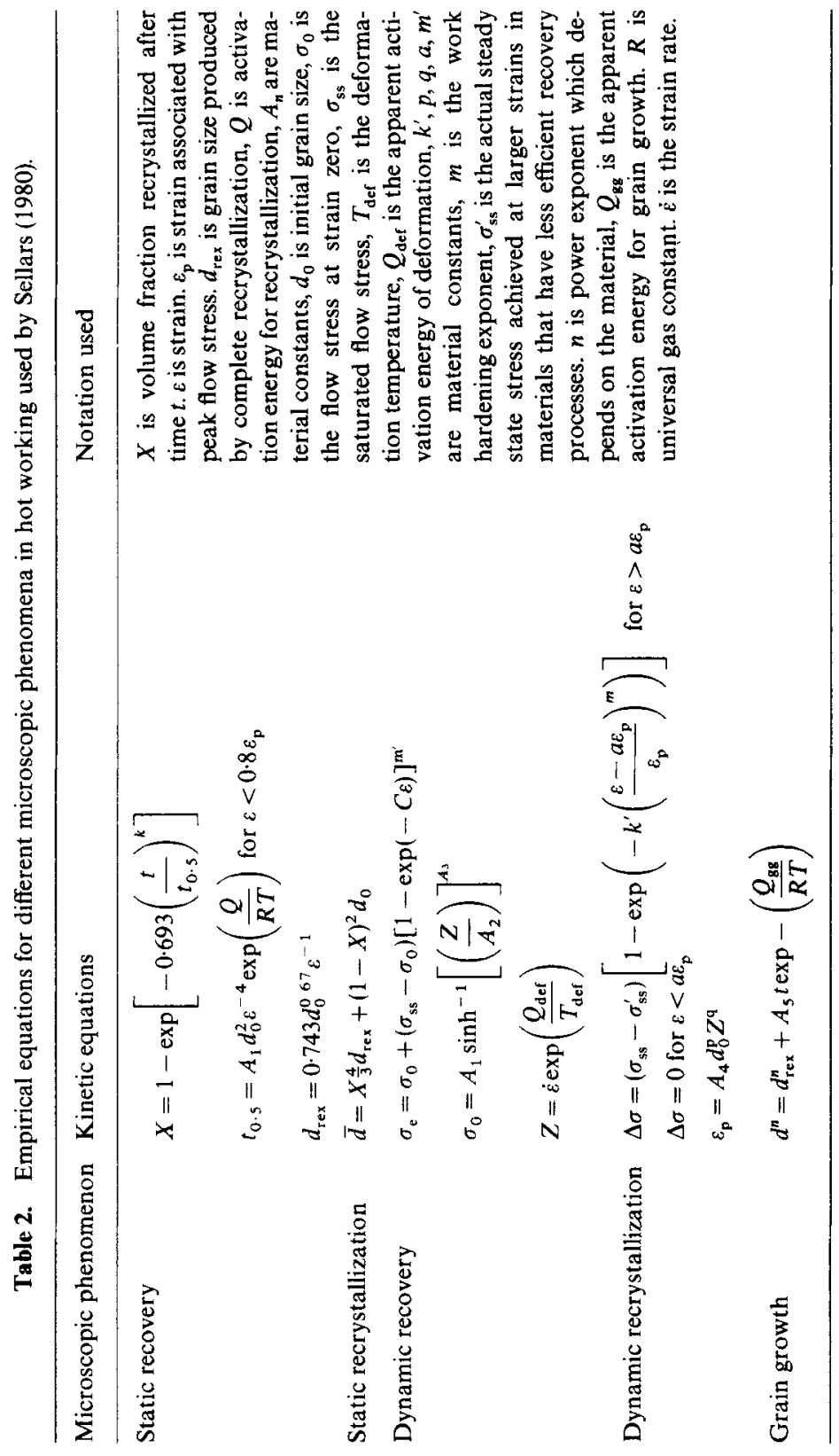


Talbot 1980; Roberts 1985a; Saito et al 1985; Choquet et al 1986; Yada 1987; Laasraoui and Jonas 1991; Yoshida et al 1991; McLaren and Sellars 1992; Najafi-zadeh and Jonas 1992; Cetlin et al 1993). Sellars (1980) gave the evolution equations for low carbon steels. He has presented a set of empirical equations relating important metallurgical variables to the Zener-Hollomon parameter, time, temperature and grain size (table 2). These equations allow prediction of peak strain, fraction of softening, time for $50 \%$ recrystallization, the recrystallized austenitic grain size, and the ferrite grain size after cooling. Pietrzyk et al $(1993,1994)$ connected a thermomechanical treatment of the flat rolling process with the Sellars equations and calculated the grain sizes as they develop in a seven stand finishing mill.

The following points summarize the current status of this approach:

(i) The microstructural evolution equations in this approach are obtained from isothermal laboratory tests. However there may be a temperature distribution in the workpiece due to heat transfer or plastic deformation. Such distributions could be predicted by the finite element method but cannot be made use of in this methodology.

(ii) While the approach provides information about the structure and properties that will be produced in a specific material subjected to a preassigned processing schedule, the calculations are required to be repeated afresh for any changed schedule or a new material. At present this methodology has been applied for the hot rolling of only a few materials such as HSLA steels and C-Mn steels which are usually processed by controlled rolling.

(iii) Some of the empirical equations used to predict the evolution of microstructural parameters are fitted with data from hot torsion tests where strain rates obtainable are smaller by one or two decades compared to the actual process being simulated and necessitating corrections to the equations (Medina and Lopez 1993). The uncertainty introduced by corrections can be avoided by using high strain rate compression tests. While in principle any manifestation of microstructural change can be modeled by a suitable phenomenological kinetic equation, the Sellars methodology has not been used so far to track changes in microstructural parameters of materials systems where there exist multiple phases or when phenomena like superplastic flow, coarsening or dissolution of some of the constituent phases or texture softening or hardening is involved.

It has been realized that none of the models proposed under this methodology will be accepted by the engineer until a full substantiation is performed by considering the grain structures obtained under industrial conditions. Sellars (1990) while comparing the predictions of several sets of empirical equations, emphasized the need to do further work in order to generate the basic flow curve data and improve the modeling of kinetics of microstructural changes.

\subsection{Hot integrated mathematical simulation (HIMS)}

A significant recent development is an integrated approach to metal forming which aims to bring in the work of several investigators under a common umbrella called HIMS (Yoshida et al 1991).

This simulation procedure can estimate simultaneously the temperature, working force and torque as well as the metallurgical properties (yield stress, grain size) from the 
exit of the reheating furnace to the finish of the final forming operation and subsequent cooling. It combines the finite element method of flow simulation in hot working with heat transfer analysis and the Sellars methodology described above. The metal forming system is considered to comprise three simulators which are mutually coupled namely, the temperature simulator, the deformation resistance simulator and the metallurgy simulator. The deformation resistance simulator estimates parameters such as load, torque and motor power required for shape change, as well as the strain and stress distributions in the component. The temperature simulator estimates the temperature of the workpiece and the tooling. The metallurgy simulator estimates metallurgical properties like austenite grain size, the effect of phase transformations and the mechanical properties produced in the end product. This approach is useful in establishing an industrial work schedule for bulk production employing a given forming process. Like the other methods described above, the HIMS does not consider the problem of defining and characterizing the hot workability of the workpiece material.

\section{Models of intrinsic hot workability}

Intrinsic hot workability may be defined as the innate capacity of a material to undergo shape change during hot working. In the models defining hot workability, a macroscopic parameter is defined in such a way that it can be easily evaluated from laboratory generated test data. The purpose is to determine the optimum working conditions of temperature and strain rate for hot working.

There are several microscopic phenomena which take place either simultaneously or in isolation in the deforming work piece such as dynamic recovery, dynamic recrystallization, dissolution and growth of particles, superplasticity, dynamic strain ageing, adiabatic shear banding, void formation at hard particles, wedge cracking at grain boundary triple points, spheroidization of acicular and lamellar microstructures and reversal of strengthening mechanisms. Depending upon the nature of the material system and the processing conditions employed, different microscopic phenomena may participate in the evolution of structure during hot working. The occurrence of any microscopic phenomenon usually has a bearing on the flow stress. The chosen intrinsic hot workability parameter should be a sensitive function of the kinetics of the microscopic phenomena. The interpretation of processing maps based on the intrinsic hot workability parameter would be facilitated by the understanding of micromechanistic maps such as that proposed by Raj.

\subsection{Raj micromechanistic map}

The Raj map is a plot in the strain rate and temperature space (Raj 1981). It shows the boundaries delineating the occurrence of different microscopic phenomena in the deforming solid. Such maps may be plotted to cover the warm and hot working temperature ranges of the material. Construction of the map involves first the selection of probable microscopic phenomena. Appropriate equations are used to estimate the bounds of temperature and strain rates for these different microscopic phenomena. The areas enclosed by these bounds are the domains in which the particular microscopic phenomenon will prevail in metal deformation. The equations used to specify the bounds are obtained from suitable phenomenological and kinetic models. The 
Table 3. The equations of micromechanisms used in the construction of Raj map (Raj 1981).

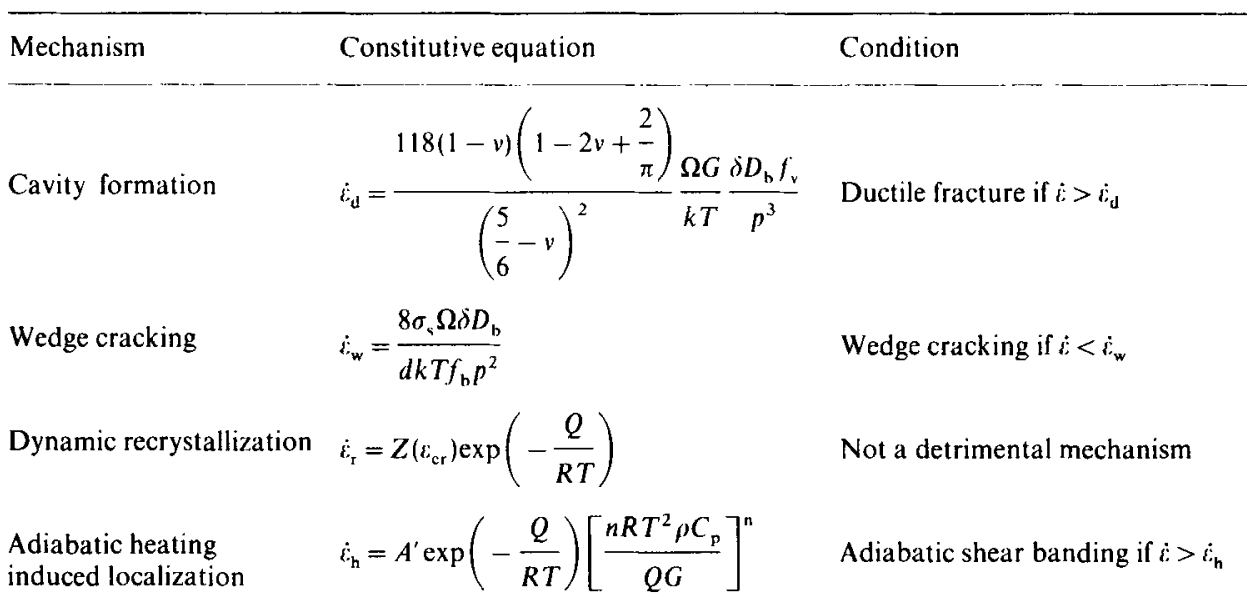

$D_{\mathrm{v}}$ and $D_{\mathrm{b}}$ are diffusivities, $Q$ is the activation energy. $k T$ has usual significance, $Z$ is a function of strain rate defined at a given strain, $G$ is shear modulus, $C_{\mathbf{p}}$ is specific heat, $\rho$ is density, $t_{c r}$ is critical strain for DRX, $n$ is a dimensionless constant, $v$ is Poisson's ratio, $p$ is particle diameter, $f$ is particle volume fraction, $d$ is the grain size, $f_{b}$ is the area fraction of the grain boundaries covered by the particles, $\Omega$ is atomic volume, $\delta$ is the grain boundary thickness, $\sigma_{\text {, }}$ is the flow stress, $R$ is the gas constant.

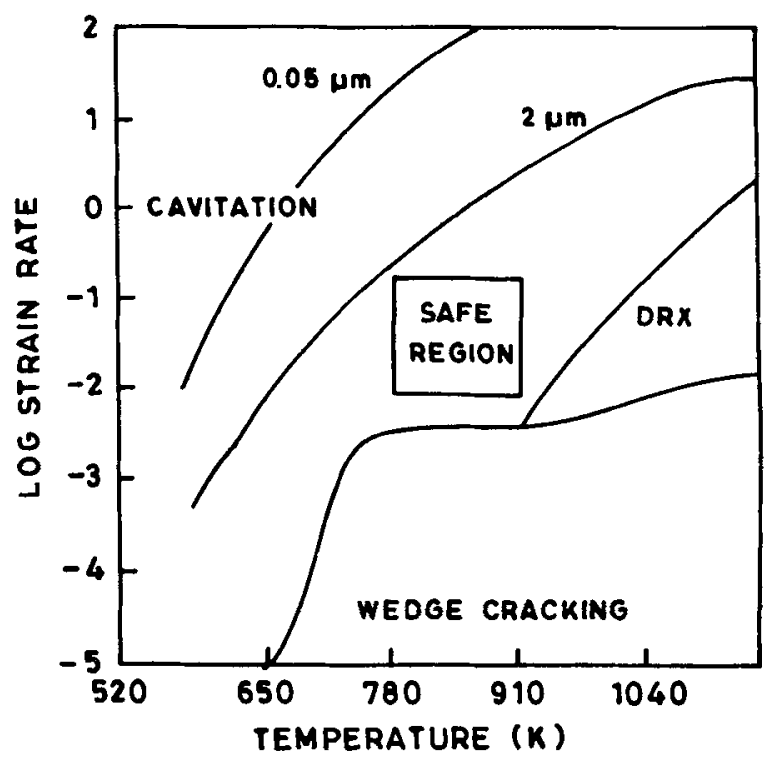

Figure 3. Raj micromechanistic processing map for commercial purity titanium. Boundary delineating ductile fracture shown for two inclusion sizes: $0.05 \mu \mathrm{m}$ and $2 \mu \mathrm{m}$.

phenomena chosen by Raj for plotting a map for aluminum are dynamic recrystallization, adiabatic shear banding, wedge cracking at grain boundaries and cavity nucleation at hard second phase particles. Using the equations proposed by Raj, given in table 3 , a processing map has been constructed by the present authors, for commercial purity titanium (figure 3 ). 
The workability window shown in figure 3 avoids the regions of undesirable phenomena like flow localization and fracture.

Elegant looking and easily interpreted, the Raj processing map is nevertheless purely micromechanistic. Validity of the model kinetic equations for complex alloys is uncertain. Further, in order to plot the map a variety of experimental data are required. Construction of the Raj processing map is possible only when considerable knowledge about the material is already available. The domains in the map are sensitive to the assumptions made regarding the microstructural features. For example, the cavitation domain boundary would depend sensitively on the assumed size and the spatial distribution of second phase particles (figure 3). Few maps of the Raj variety have been constructed for engineering alloys. A really significant breakthrough in modeling hot workability has occurred with the introduction of the dynamic materials model.

\subsection{The dynamic materials model}

The dynamic materials model, proposed by Gegel and coworkers (Gegel et al 1988) and popularized in India by Prasad and co-workers (Prasad et al 1984; Prasad 1990), arose from considerations of physical systems modeling of Wellstead (1979). In formulating the model the proponents were seized of the question "how does the workpiece respond to the demands imposed on it by the hot working operation?" They postulated that the workpiece responds by exhibiting those processes which would maximize the rate of dissipation of energy. They visualized the metal working environment to be a system comprising three basic elements namely, the materials system, the control system and the equipment and tooling system respectively. The dynamic materials model is the connecting link between the material system and the control system. It considers the workpiece in hot working to be a nonlinear dissipator which dissipates energy as viscous heat and internal structural changes. This conceptualization allows one to treat the problem macroscopically, thereby avoiding the consideration of operative atomic processes (Gegel 1988).

In the dynamic materials model the total instantaneous power is split into two components $G$ and $J$ as in (1). The splitting is substantiated by a convex extremum principle known as the maximum rate of entropy production (Ziegler 1963).

$$
\int \mathrm{d} P=S \dot{E}=\int_{0}^{E} S \mathrm{~d} \dot{E}+\int_{0}^{S} \dot{E} \mathrm{~d} S=G+J,
$$

where $S$ and $E$ are the instantaneous flow stress and the strain rate respectively. The quantity $G$, which is given by the area under the true stress-true strain rate diagram, is designated as dissipator power content and its complementary component $J$ as dissipator power co-content. $J$ in the model is assumed to be related to microstructural changes occurring with deformation while $G$ is related to continuum effects.

From the convexity between a set of potential functions in stress and strain rate spaces, as postulated by Ziegler, it is possible to obtain the constitutive relation for a material system undergoing deformation as

$$
S=C \dot{E}^{m},
$$

where $C$ is a material constant and $m$ the strain rate sensitivity. 
In the dynamic materials model, $J$ is used to grade the hot workability of different materials. Since $J$ is a function of strain rate and temperature, it is used to define the best operating conditions for hot working a given material by choosing a reference condition of the material. An ideally viscous material obeys the constitutive relation in (2) with $m=1$. For this condition $J=J_{\max }$. Hence it is possible to define a ratio

$$
\eta=\frac{J}{J_{\max }}=\frac{2 m}{m+1} .
$$

The dimensionless parameter $\eta$ is called the dissipation efficiency parameter because it is considered to describe how well the workpiece dissipates power by microstructural changes relative to an ideal viscous condition. Optimum hot working conditions are deduced from the dissipation efficiency maps which show the variation of $\eta$ in temperature and strain rate space.

For plotting $\eta$ maps, true stress-true strain data are determined from simple tests such as uniaxial tension, compression or torsion at several combinations of strain rate and temperature. From these flow stress values the dissipation efficiency maps are plotted by numerical interpolation and differentiation. Gegel (1988), Padmavardhani and Prasad (1992) and Zhao et al (1992) have constructed the dissipation efficiency maps for a number of metals and alloys, including Ti-6242, nimonic alloys, titanium and nickel aluminides, copper alloys, aluminum and its alloys, nickel and its alloys, stainless steels, zirconium alloys and several other materials. Peaks and valleys in these

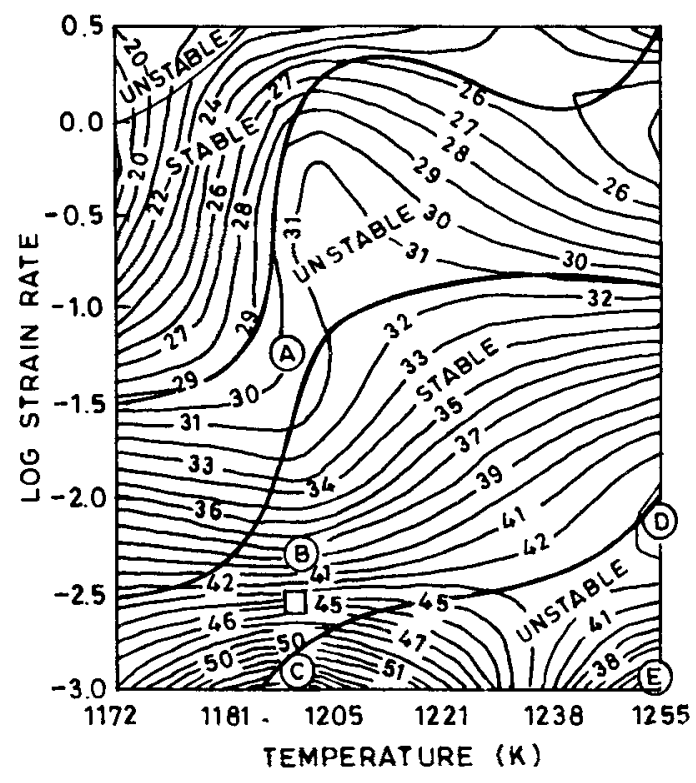

Figure 4. A processing map of dynamic materials model.

The instability parameter contours are superposed on the dissipation efficiency map to separate out the stable working conditions from unstable regions. The micromechanisms identified by metallography are marked by capital letters: [A] Wedge cracking at grain boundaries; [B] $x$ phase with wedge morphology; [C] Kinking and spheroidization; [D] Cavities at grain boundary triple points: [E] Transformed $\alpha$ in $(\alpha+\beta)$ matrix. The recommended processing window is shown by a rectangle (Gegel 1988). 
maps may be associated with certain microstructural changes. A representative map is shown in figure 4 for an $(\alpha+\beta)$ titaniurn alloy $\mathrm{Ti}-6 \mathrm{Al}-2 \mathrm{~V}-4 \mathrm{Mo}-2 \mathrm{Cr}$. This map shows an $\eta$ peak around $1200 \mathrm{~K}$ and $10^{-1} \mathrm{~s}^{-1}$ w'aich is associated with the occurrence of dynamic recrystallization of the $x$ phase.

Different microscopic phenomena have different dissipation efficiencies and other characteristic features which help in their identification in the map. Microscopic phenomena which are beneficial to hot workability such as dynamic recovery and dynamic recrystallization display high dissipation efficiencies. However, since microscopic phenomena detrimental to hot workability such as cracking and void formation also possess high dissipation efficiencies, a means of separating them from the former is required in order to use the dissipation efficiency maps for deciding the optimum hot working conditions. For this purpose regions in the map associated with instabilities are identified with the help of suitable instability criteria (Malas 1985; Kumar 1987; Gegel et al 1988). According to Gegel (1988) only after superimposition of the instability contours can the dissipation efficiency map be considered a "processing" map.

The strength of the dynamic materials model is that it captures the most important characteristic of the deforming workpiece in hot working namely, the strain rate dependence of the flow stress. Because of this fact a correlation between the topographic features in the $\eta$ map and the microscopic phenomena in the corresponding Raj map is normally found. In the dynamic materials model, the effect of strain history on the hot working schedule has not been considered to be significant. However, memory or deformation history dependence is a basic feature of metallic materials exhibiting rate insensitive flow behavior. At hot working temperatures where rate dependent flow is observed, the history dependence may be small but cannot be neglected altogether (Alexander 1989).

\subsection{Polar reciprocity model}

This model has been introduced to account for the deformation history dependence of flow stress while at the same time recognizing the strong rate dependence of flow stress as the primary flow characteristic of the workpiece (Rajagopalachary and Kutumbarao 1989).

The splitting of instantaneous power dissipated by the system can be done either as a constitutive assumption or by invoking a more fundamental principle such as the associated flow rule of plasticity. A split component may be utilized to track the rate dependence of the plastically deforming material in hot working environment. In this model, the associated flow rule of classical plasticity is used as the basis for splitting the total instantaneous inelastic power into two complementary components. This method has been adopted following Hill (1987), who established a one to one correspondence between first degree homogeneous dual potential surfaces. The procedure adopted is described below:

Figure 5 shows a convex potential surface $\Phi=K$ in stress space with origin at $O_{1}$. Let an arbitrary radius vector $O_{1} P$ at point $P$ on $\Phi$ be given. The magnitude of the normal to $\Phi$ at $P$ is scaled so that it is equal to $K K^{\prime} / O_{1} P$ where $K K^{\prime}$ is the power being expended. For every point $P$ on $\Phi$ a corresponding point $P^{\prime}$ may be found by drawing a parallel vector from $O_{1}$ in the direction $v$ with a magnitude of the scaled normal as above. The locus of the points $P^{\prime}$ then constitutes a potential surface $\Phi^{\prime}$ in strain rate 


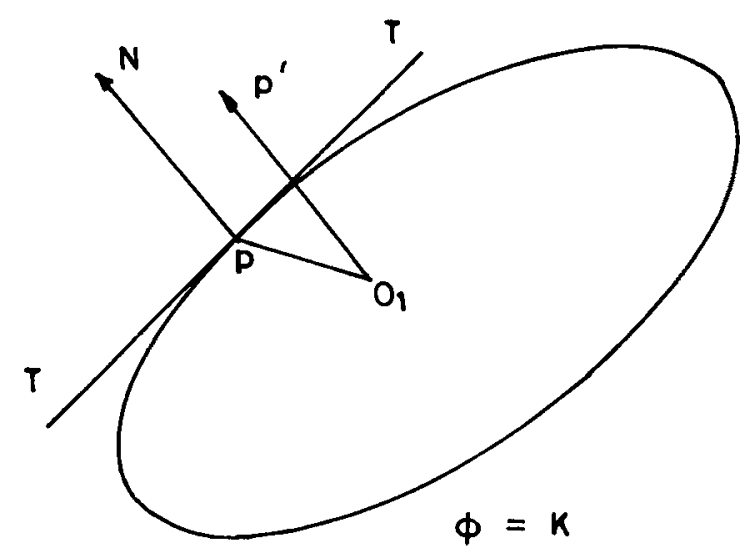

Figure 5. Pole-polar relationship between two first degree nonlinear potential functions.

space. The two potential functions have a pole and its polar plane relation. A point of discontinuity in one potential surface is associated with a straight edge or plane in the other potential surface and vice versa. The constants $K$ and $K^{\prime}$ are presumed to be scalar valued functions of deformation history and temperature. The two conjugate potential functions can be dependent on variables which may not be subject to polar reciprocity relation. The effect of strain or deformation history is taken into account with such variables. Because of the one to one correspondence between the potentials in stress and strain rate spaces the following equation is true for a given temperature and deformation history:

$$
\int_{0}^{\dot{E}^{P}} S \mathrm{~d} \dot{E}^{P}+\int_{0}^{S} \dot{E}^{P} \mathrm{~d} S=S \dot{E}^{P} .
$$

The two integrals in (4) may be called as hardening power $\dot{W}_{\mathrm{H}}$ and dissipative power $\dot{W}_{\mathrm{D}}$ respectively. The system behavior may be nonlinear but may be such that the bijective correspondence discussed above is still valid.

Once the power is split as in (4) $\dot{W}_{\mathbf{H}}$ or $\dot{W}_{\mathrm{D}}$ acquire a significance which the total power dissipated does not have. The total instantaneous power reflects the current condition of the material as specified by the current flow stress and the current imposed strain rate. A parameter to characterize the material behavior can be defined by using either $\dot{W}_{\mathrm{H}}$ or $\dot{W}_{\mathrm{D}}$. In this model an intrinsic hot workability parameter based on $\dot{W}_{\mathrm{H}}$ is defined as

$$
\zeta=\left(\frac{\dot{W}_{\mathrm{H}}}{\dot{W}_{\mathrm{Hmin}}}-1\right) .
$$

There could exist several material systems subject to deformation at a given strain rate and temperature and dissipating at a specified rate. It is postulated in this model that two materials with the same response $S$ and dissipating at a given rate will behave identically under all identical future stimulii during hot working provided that they have the same area under the stress-strain rate curves and possess equal values of a parameter characterizing the strain history. This postulate enables the optimum hot 
working conditions for a given material to be determined. $\dot{W}_{\mathrm{Hmin}}$ is used in (5) to normalize $\dot{W}_{\mathbf{H}}$. The normalization enables the intrinsic workability to be described in relative terms. The comparison is made with a fictitious material having the same macroscopic properties as the material under consideration, but whose $\dot{W}_{\mathrm{H}}$ is independent of strain history and whose stress-strain rate curve is linear such that $\dot{W}_{\mathrm{H}}=\dot{W}_{\mathrm{D}}$. A suitable assumption about the dependence of $\dot{W}_{\mathrm{D}}$ on the strain history enables us to show that the polar reciprocity and splitting of power as in (4) are valid even when the flow stress developed in the body is of the form

$$
S=H\left(E^{P}\right)+C F\left(\dot{E}^{P}\right)
$$

where $H\left(E^{P}\right)$ and $C$ are different functions of strain history. If the effect of the strain is to shift the potential surfaces in stress with respect to the origin then we have a contribution to $H\left(E^{P}\right)$. If the effect of the strain is to scale the potential surface in the stress space, such as in isotropic expansion or contraction, then the change is reflected in the value of $C$. Equation (6) will represent a generalized Malvern material if $C$ is constant. The term $H\left(E^{P}\right)$ in this case is considered as exclusively dependent on the strain history and the temperature. In polar reciprocity model a constitutive assumption is made that $H\left(E^{P}\right)$ is given by

$$
H\left(E^{P}\right)=S \frac{\left(\int_{0}^{E_{1}} S \mathrm{~d} E-\int_{0}^{E_{1}} S_{\min } \mathrm{d} E\right)}{\int_{0}^{E_{1}} S \mathrm{~d} E}
$$
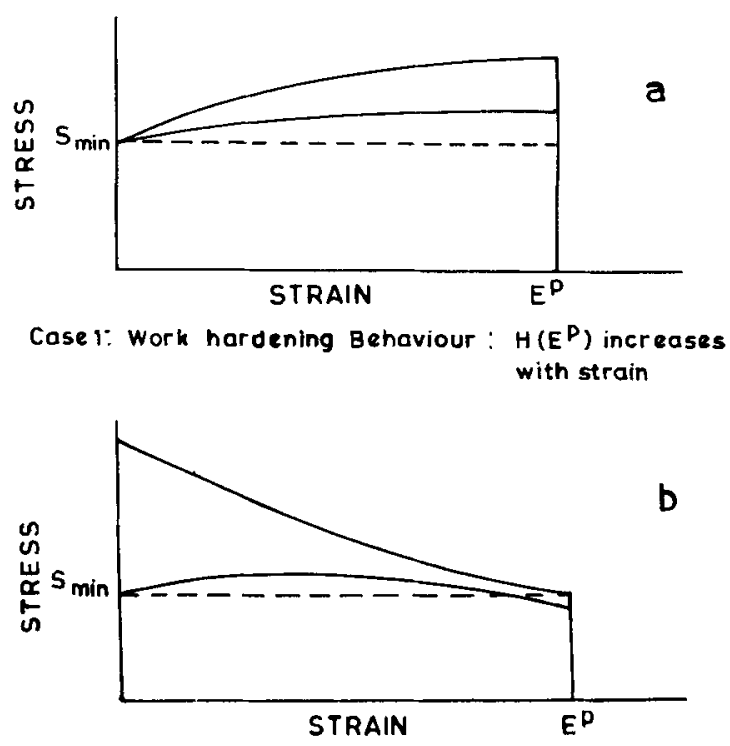

Case 2 : Flow softening: $H\left(E^{P}\right)$ decreases and levels off

Figure 6. Choice of history function in polar reciprocity model and its nature when the material exhibits (a) strain hardening and (b) strain softening. When ideal plastic flow occurs the history function has zero magnitude. 
as a measure of strain history until a strain $E_{1}$ is accumulated. The stress-strain rate curve may be plotted at strain $E_{1}$. A sort of fading memory of the material's state at the beginning of plastic flow with increasing strain is implied by (7). The implications of this definition of history function are shown in figure 6. For a work-hardening material $H\left(E^{P}\right)$ increases with strain. It asymptotically decreases with strain when strain softening occurs. Its magnitude is zero for ideal plastic behavior, in which case it may be assumed that strain rate sensitivity is the only factor controlling intrinsic hot workability.

It can be proved that the following power law is valid when polar reciprocity exists between two convex potential functions $\Phi$ and $\Phi^{\prime}$, i.e.

$$
F\left(\dot{E}^{P}\right)=\left(\dot{E}^{P}\right)^{m^{\prime}}
$$

where $m^{\prime}$ is a modified strain rate sensitivity exponent. From (5)-(8) the polar reciprocity model arrives at a measure of intrinsic hot workability termed $\zeta$ as

$$
\zeta=1-\left[\frac{2 m^{\prime}}{m^{\prime}+1}\right]\left[\frac{S-H\left(E^{P}\right)}{S}\right] .
$$

When the material exhibits ideal plastic flow the history function defined by (7) would be zero and the strain rate sensitivity exponent, $m^{\prime}$ in (9) becomes equal to the conventional strain rate sensitivity $m$ used in (2). In this event, the dissipation efficiency $\eta$ defined in (3) and the hot workability parameter $\zeta$ sum to unity. It follows that features that are identified as hills in the $\eta$ maps reproduce as basins or lakes in $\zeta$ maps and vice versa. Thus the predictions of the polar reciprocity model are identical to those of the dynamic materials model in the absence of strain history dependence.

Tests such as uniaxial compression or plane strain compression at several hot working temperatures and strain rates are adequate for the evaluation of $\zeta$. The chosen temperatures and strain rates form a grid of points in temperature and strain rate space. A $\zeta$ map may be constructed at a strain $E_{1}$ as follows. From the true stress-true strain diagram the flow stress at $E_{1}$ is known. The area under the flow curve up to $E_{1}$ can be determined by numerical quadrature. The minimum stress in flow curve up to $E_{1}$, i.e. $S_{\text {min }}$, is determined. The product $S_{\min } E_{1}$ is subtracted from the area determined by numerical quadrature. This difference is normalized by the area under the flow curve up to $E_{1}$. This fraction equals to $H\left(E^{P}\right) / S$ which is the ratio of strain history dependent component of flow stress to the flow stress. This procedure may be repeated for flow curves obtained at all the grid points chosen for testing in the temperature-strain rate space. From the strain rate dependent components of flow stress at these grid points, obtained by using (6), the modified strain rate sensitivity exponent $m^{\prime}$ can be determined by numerical differentiation. Since $m^{\prime}, H\left(E^{P}\right)$ and $S$ are known at each of the data points, $\zeta$ can be evaluated. Zeta values at several combinations of temperature and strain rate are used to construct two-dimensional contour maps and three-dimensional surface plots at a given $E_{1}$. Several such maps can be plotted for a given material at different plastic strains.

The $\zeta$ maps exhibit different topographic features (figure 7). An elaborate exercise has been carried out by Rajagopalachary (1994) to establish a correspondence between the topographic features in the $\zeta$ maps of titanium alloys and the microscopic phenomena that take place concurrently with shape change. This exercise included a close examination of post-deformation microstructures and the phenomenological 

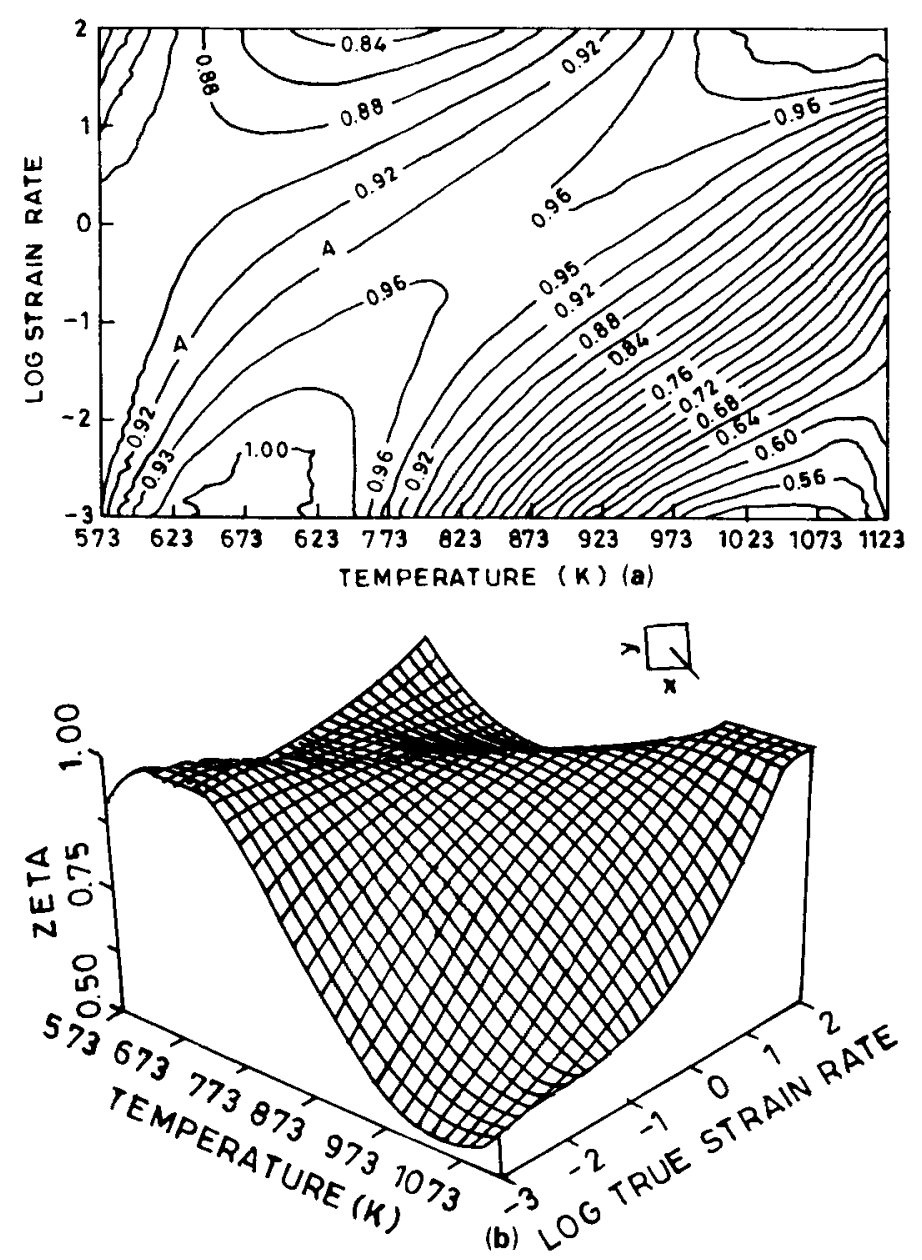

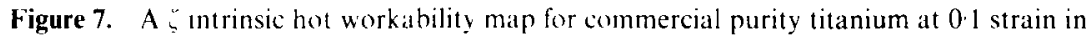
compression. (a) Two-dimensional contour plot and (b) three dimensional surface plot of $\zeta$ in temperature strain rate space.

Table 4. The microscopic phenomena observed durng hot compression of titanium alloys and the corresponding values.

\begin{abstract}
Microscopic phenomena
Cracking, shear banding, adiabatic shear banding, grain growth, dynamic strain ageing

$0.81 \cdot 0$

Cavitation at grain boundaries. dynamic recovery. dynamic recrystallization

$0.7-0.8$

Dynamic recovery, dynamic recrystallization, grain pinching, texture softenıng, superplasticity

$0 \cdot 5-0 \cdot 7$

Superplasticity

$<0.5$
\end{abstract}

characteristics of deformation. Some of the important conclusions that emerge from this study are: (1) Phenomena involving creation, rotation and migration of interfaces in the material result in $\zeta$ basins in the maps. This is the case with phenomena like superplasticity (Rajagopalachary and Kutumbarao 1996), spheroidization of lamellar 

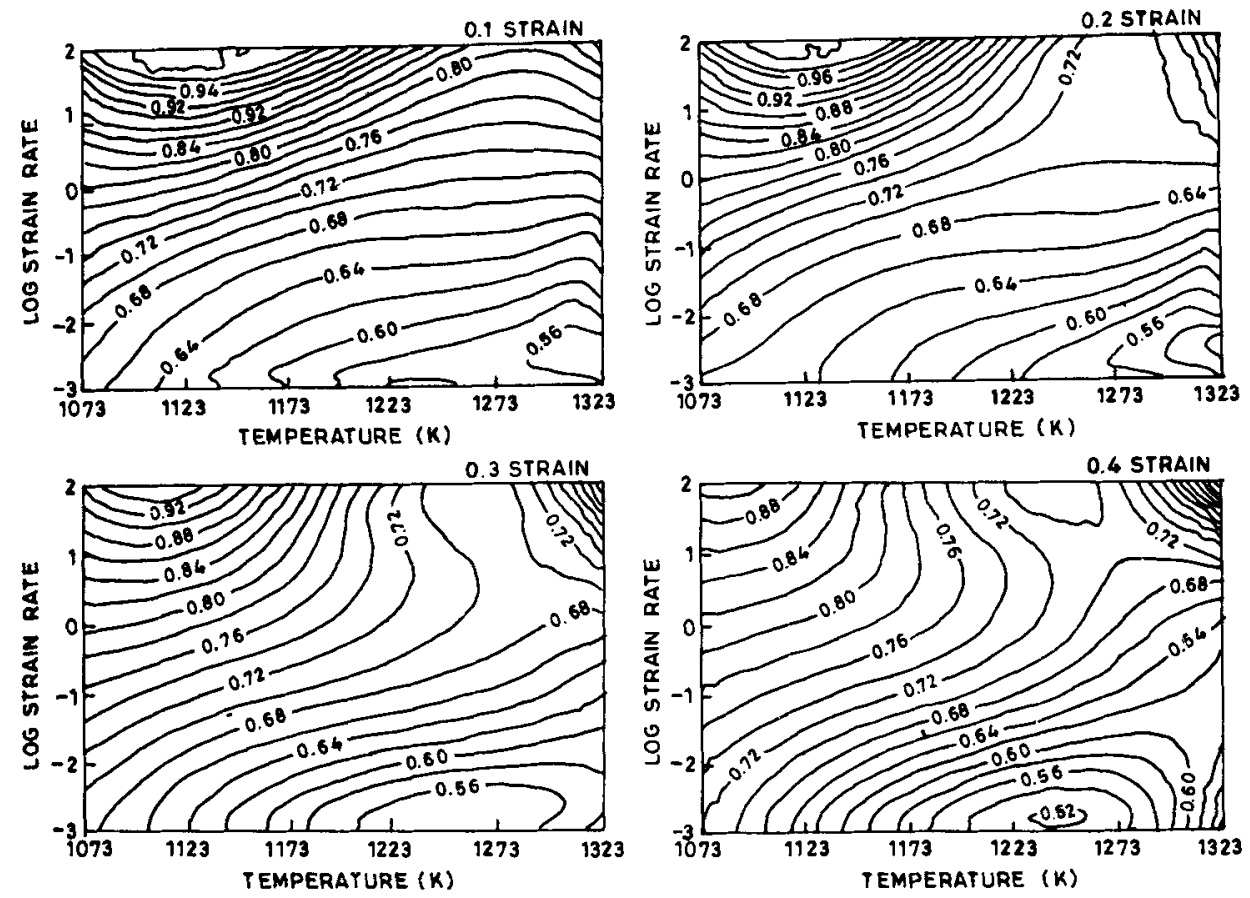

Figure 8. $\zeta$ maps of BT9 illustrating the shift of domains with strain. A shift of lake bottom from $1323 \mathrm{~K}$ and $5 \times 10^{-3} \mathrm{~s}^{-1}$ at 0.1 strain to $1263 \mathrm{~K}$ and $3 \times 10^{-3} \mathrm{~s}^{-1}$ at 0.4 strain can be noticed.
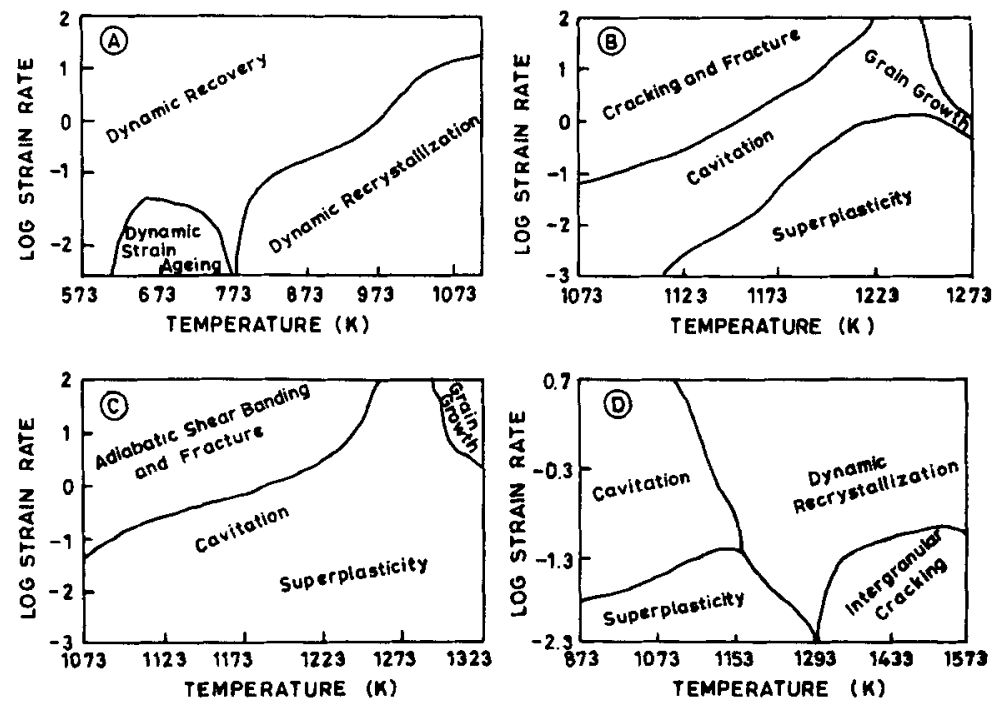

Figure 9. Domains of different microscopic phenomena in the $\zeta$ maps of several titanium alloys. (a) Commercial purity titanium at 0.4 strain in compression, (b) IMI685 at 0.3 strain in compression, (c) BT 9 at 0.4 strain in compression and (d) Ti-15333 at 0.3 strain in tension. 


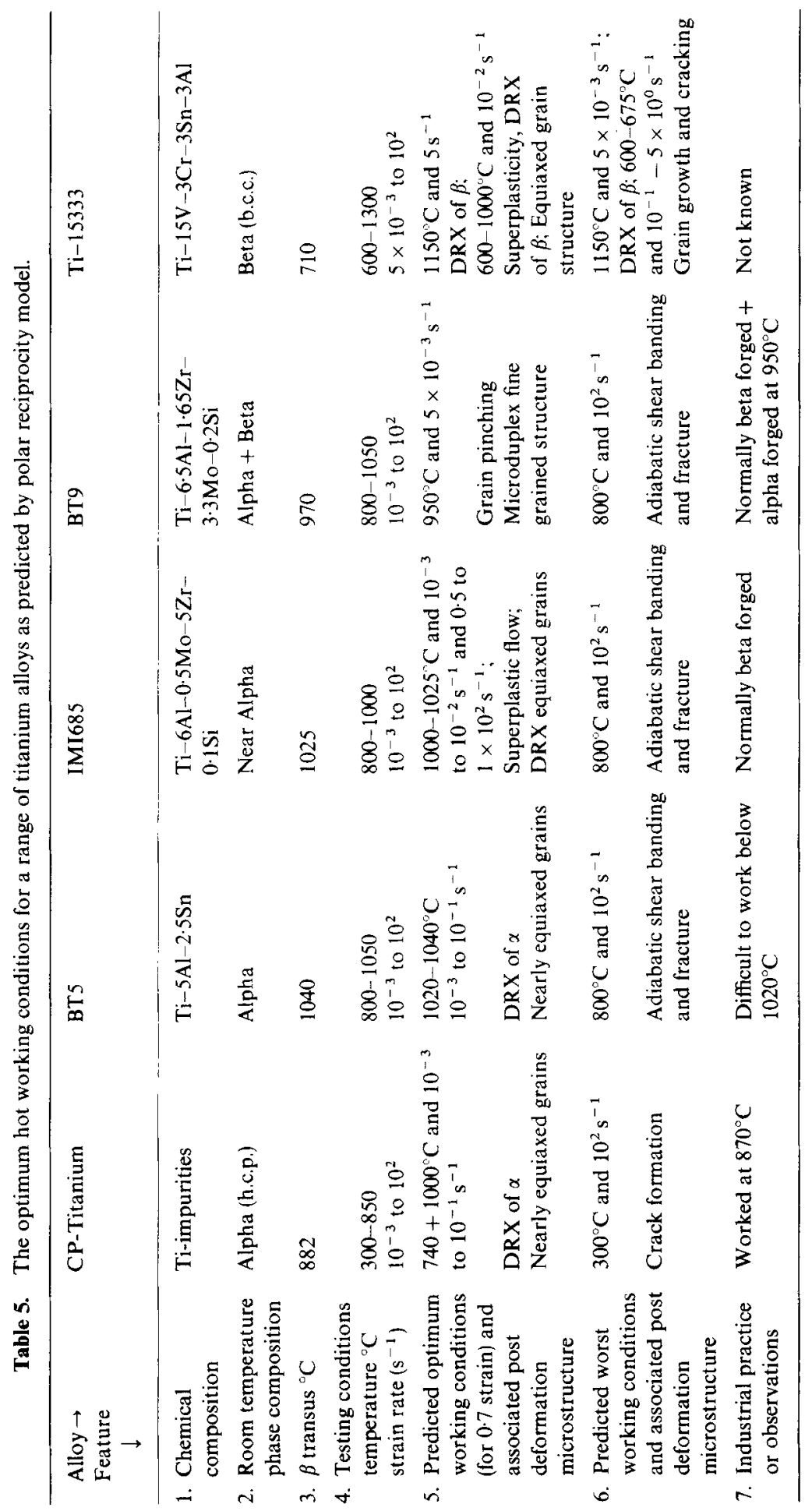


phases and dynamic recrystallization. The $\zeta$ basins are considered to be repositories of good intrinsic hot workability. (2) Grain growth would cause large increase in $\zeta$ and poor intrinsic hot workability. Flow localization that leads to adiabatic shear banding and fracture would also produce high $\zeta$ hills or plateaus. A correspondence between the magnitude of $\zeta$ and the microscopic phenomena that were observed is given in table 4 .

Many microscopic phenomena are known to possess their own characteristic strainthresholds for initiation. The characteristic strain threshold as also the kinetics of the phenomena may be functions of strain rate and temperature. Such functional dependency produces motion of domains in the $\zeta$ map with plastic strain. This may be illustrated by the behavior exhibited by $(\alpha+\beta)$ titanium alloy BT9 (figure 8). This alloy exhibits a microscopic phenomenon called grain pinching over a temperature range 1173-1243 K and strain rate range of $10^{-3} \mathrm{~s}^{-1}$ to $10^{2} \mathrm{~s}^{-1}$. This is a structure homogenization process in which the interface between the $\alpha$ and $\beta$ phases breaks down. The local protrusions or necks pinch the other phase progressively, to produce an equiaxed and refined grain structure. In this process a large interfacial area is created. Corresponding to this process a $\zeta$ basin is seen in the processing map of the alloy. This domain would shift from a high temperature to a low temperature as strain is increased. Such observations have the implication that (i) $\zeta$ could vary sensitively with the plastic strain and (ii) while predicting the optimum conditions of hot working from the $\zeta$ maps, the magnitude of plastic strain the workpiece is likely to experience should also be considered.

Figure 9 shows the domains of prevalence of some microscopic phenomena in a range of titanium alloys identified on the basis of the corresponding $\zeta$ maps. A good agreement has been found between the optimum working conditions predicted by the polar reciprocity model and the industrial working schedules for the titanium alloys studied. This is evident from table 5 .

An important feature of the processing maps for titanium alloys based on the polar reciprocity model is that microscopic phenomena which promote good workability occupy regions that are sufficiently distinct from those occupied by phenomena which are detrimental to workability. The associated flow rule of plasticity, on which the polar reciprocity model rests, is based on the convexity of potential functions. The hardening power term $\dot{W}_{\mathrm{H}}$ increases monotonically to attain a high value and $\zeta$ tends to 1 at very large strain rates where the associated flow rule fails. The dissipative power component $\dot{W}_{\mathrm{D}}$ exhibits a cusp catastrophe under these conditions and the material shows a macroscopic instability in flow behavior. Thus a $\zeta$ value approaching 1 is definitely a condition of instability. Hence the superposition of a separate stability condition on the $\zeta$ maps is not considered necessary.

While the polar reciprocity model is based on continuum approximation of the material, it may be possible to reformulate it for composite materials where more than one phase coexist. Composite materials, which are of topical interest, most often have microstructural periodicity. Such materials can be modeled by a mathematical homogenization process.

\section{Conclusions}

Recent developments in mathematical modeling of hot working strive to satisfy the increasingly exacting demands of the forming engineer charged with producing sound components at minimum cost. Simulation of metal flow during hot working has been attempted. Integrated simulations of a coupling between metal flow, heat transfer and 
phase change are well formulated but have to mature into applications. The algorithms for calculating the microstructural parameters are reasonably well established. Such calculations may become routine in determining the optimum deformation sequences in rolling mills. Experimental validation of the predictions made by this methodology by data from industrial rolling schedules is inadequate even for the hot rolling schedules that were modeled. The equations employed in the methodology need to be developed and evaluated for other hot working processes as well. Intrinsic hot workability studies are likely to become an integral part of material development and characterization programs. The predictions of the polar reciprocity model and the dynamic materials model look very promising for homogeneous materials. For solids which are aggregates of discrete phase particles with macroscopic dimensions, there is a necessity of redefining the intrinsic hot workability measures. Interesting results may be expected to emerge when the three listed directions of mathematical modeling are combined into a unified approach.

\section{Acknowledgement}

The authors express their gratitude to Prof. Y V R K Prasad, Department of Metallurgy, Indian Institute of Science, Bangalore for kindling their interest in hot workability studies and also for providing experimental facilities. They are indebted to Dr P Rama Rao, Defence Research and Development Organization, Government of India, for his keen interest in this work and constant encouragement.

\section{References}

Ahlblom B and Roberts W 1979 Optimization of processing, properties and service performance through microstructural control, ASTM STP 672 Philadelphia USA, 296

Alexender J M 1989 Modeling of hot deformation of steels (ed.) J G Lenard (Berlin: Springer-Verlag) p. 101

Altan T and Lahoti Gi D 1979 Ann. CIRP 28473

Altan T, Oh S I and Gegel H L 1983 Metal forming (Metals Park, Ohio, USA: ASM International)

Amici E, Demofonto G, Lubrano M, Pietrosanti N and Kapaj N 1989 Proc. Conf. NUMIFORM'89 (eds) E G Thompson et al (Rotterdom: A A Balkema)

Argyris J H and St Doltsinis 1981 J. Comp. Meth. Appl. Mech. Engg. 2531

Badawy A. Oh S I and Altan T 1983 Proceedings of ASME conference of computer engineers, (Chicago: ASME) 132

Beynon J H. Brown P R, Mizban S I, Ponter A R S and Sellars C M 1986 Proc. Conf. NUM1FORM'86 (eds) K. Mattiasson, R Samuelsson, D Wood and O C Ziienkiewicz (Rotterdam: A A Balkema) p. 213

Blazynski T Z 1983 Applied elastoplasticity of solids (London: Macmillan Press) p. 74

Boer C R and Rydstad H 1984 J. Appl. Metal Working 3421

Cetlin P R, Yue S and Jonas J J 1993 Materials Forum 14245

Choquet P, Lebon A and Perdrix Ch 1986 ICSM A-7 (eds) H J McQueen, J P Bailon, J J Dickson and J J Jonas 21025

Collins I F 1968 J. Mech. Phys. Solids 16137

Gegel H L 1988 Computer simulation in muterials science (Metals Park Ohio: ASM International) p. 291

Gegel H L, Malas J C. Doraivelu S M and Shende V A 1988 Metals Handbook 14 Forming and forging (Metals Park, Ohio: ASM International) p. 407

Gelten C J M and Konter A W A 1982 Proc. Conf. NUMIFORM 82 p. 511

Grober H, Charlier R and Cescotto C 1986 Proc. Conf. NU MIFORM 89 (eds) E G Thompson et al (Rotterdam: A A Balkema!

Hill R $1987 J$. Mech. \& Phys. Solids 3523

Huetink J 1982 Proc. int conf. numerical methods in industrial forming processes (Swansea, UK: Pineridge Press) p. 501 
Huetink J, Van Del Lugt and Vreede T 1988 in Modelling of metal forming processes (eds) J L Chenot and E Onate (Amsterdam: Kluwer)

Johnson W, Sowerby R and Venter R D 1982 Plane strain slip-line fields for metal deformation processes (Oxford: Pergamon Press)

Kobayashi S 1982 J. Appl. Metal Working 2163

Kopp R, De Souza M M, Dahl W and Hagen M 1988 Steel Res. 59542

Kumar A K S 1987 Criteria for predicting metallurgical instabilities in processing, MS Thesis, I.I.Sc., Bangalore Laasraoui A and Jonas J J 1991a Metall. Trans. A22 1545

Laasraoui A and Jonas J J 1991b ISIJ International 3195

Malas J C 1985 A thermodynamic and continuum approach to the design and control of precision forging processes, MS Thesis, Wright State University, Dayton, Ohio, USA

McLaren A J and Sellars C M 1992 Mater. Sci.\& Technol. 81090

Medina S F and Lopez V 1993 ISIJ International 33605

Montmittonnet P and Buesler P 1991 ISIJ International 32213

Naghdi P M 1990 J. Appl. Maths. \& Phys. (ZAMP) 41315

Najafi-zadeh A and Jonas J J 1992 ISIJ International 32233

Owen D R J and Hinton E 1980 Finite elements in plasticity (Swansea UK: Pineridge Press)

Padmavardhani D and Prasad Y V R K 1992 Mater. Sci. Eng. A155 245

Parthington D and Talbot I 1980 Hot working and forming processes (eds) C M Sellars and G J Davies (London: Institution of Metallurgists) p. 176

Pietrzyk M 1986 Proc. Conf. NUMIFORM'86 Gothenberg (eds) Mattiasson et al (Rotterdam: A A Balkema)

Pietrzyk M, Kedzierski Z, Glowacki H, Kusiak H and Sinczak J 1994 Steel Res. 6595

Pietrzyk M, Kedzierski Z, Kosiak H, Madej W and Lenard J G 1993 Steel Res. 64248

Prasad Y V R K 1990 Indian J. Technol. 28435

Prasad Y V R K, Gegel H L, Doraivelu S M, Malas J C, Morgan J T, Lark K A and Barker D R 1984 Metall. Trans. A11 1883

Raj R 1981 Metall. Trans. A12 1089

Rajagopalachary T 1994 Hot workability studies in titanium and its alloys, PhD Thesis, Banaras Hindu University, Varanasi, India

Rajagopalachary T and Kutumbarao V V 1989 Metals, Mater.\& Process. 157

Rajagopalachary T and Kutumbarao V V 1996 Scr. Metall. \& Material (to appear)

Rantanen A, Malinen M, Ranta H and Kerhonen A S 1989 Proc. Conf. NUMIFORM'89 (eds) E G Thompson, R G Wood, O C Ziienkiewicz, A Samuelsson and F F Collins (Rotterdam: A A Balkema) p. 355

Rebelo N and Kobayashi S 1980 Int. J. Mech. Sci. 22699

Roberts W 1985a Deformation processing and structure (ed.) G Krause (Metals Park Ohio: ASM) p. 109

Roberts W 1985b Proc. ICSMA 7 (eds) H J McQueen, J P Bailon, J I Dickson, J J Jonas and M K Akben (London: Pergamon Press) 31859

Roberts W, Sandberg A, Siwecki T and Werlefors T 1984 HSLA steels: Technology and applications (Metals Park Ohio: ASM International) p. 67

Saito Y, Emami T and Tanaka T 1985 Trans. Iron and Steel Inst. Jap. 251146

Sekine H, Murayama T, Kageyama H and Kawashima Y 1982 Thermomechanical processing of microalloyed austenite (eds) A J DeArdo, G A Ratz and P J Wray (Warrendale: Met. Soc. AIME) p. 41

Sellars C M 1980 Sheffield inter. conf. on hot working and forming processes (eds) C M Sellars and G J Davies (England: Met. Soc.) p. 3

Sellars C M 1990 Mater. Sci. \& Technol. 6107

Sellars C M 1990 Proc. int. symp. mathematical modeling of hot rolling of steel (ed.) S Yue (Hamilton: Canada) 1

Sellars C M and Whiteman J A 1979 The Metal Science 14187

Shimazaki Y and Thompson E G 1981 Int. J. Numerical Meth. Eng. 1797

Thomsen E G, Young C Y and Kobayashi S 1965 Mechanics of plastic deformation in metal processing (New York: Macmillan)

Wellstead P E 1979 Introduction to physical systems modelling (London: Academic Press)

Yada H 1987 Proc. int. symp accelerated cooling of rolled steel (eds) G E Raddle and A F Crawley (Winnepeg, Canada: Pergamon Press)

Yoshida H, Yosifusi A, Kosiki S and Saike M 1991 ISIJ International 31571

Ziegler H 1963 Progress in solid mechanics (eds) I N Sneddon and R Hill (Amsterdam, The Netherlands: North-Holland Publishing Co.) 493

Zhao D, Tuler I R and Lloyd 1992 Scr. Metall. Mater. 2741 